\title{
Prevalence of Mild Hearing Loss in Schoolchildren and its Association with their School Performance
}

\author{
Reem Elbeltagy ${ }^{1,2}$ (1) \\ ${ }^{1}$ Audio Vestibular Unit, Ear, Nose and Throat Department, Faculty of \\ Human Medicine Ringgold Standard Institution, Zagazig University, \\ Zagazig, Egypt \\ 2 Health Communication Science Department, College of Health and \\ Rehabilitation Science, Princess Noura Bint Abdulrahman University \\ Ringgold Standard Institution, Riyadh, Saudi Arabia \\ Int Arch Otorhinolaryngol 2020;24:e93-e98.
}

\begin{abstract}
Address for correspondence Reem Elbeltagy, Audio Vestibular Unit, Ear, Nose and Throat Department, Faculty of Human Medicine Ringgold Standard Institution, Zagazig University, Zagazig, Egypt (e-mail: reem.elbeltagy@yahoo.com).
\end{abstract}

\section{Introduction}

Hearing is important for the proper development of every child, especially those younger than 5 years of age, because it helps in the development of language and speech. ${ }^{1}$ Hearing loss is considered one of the most prevalent disabling disorders worldwide; ${ }^{2}$ it affects between 1 to 6 children per

received

April 20, 2018

accepted

June 16, 2019
Introduction Hearing is important for the proper development of every child, especially for those younger than 5 years of age, because it helps in the development of language and speech. Emotional and social problems, as well as issues with academic performance, can result from hearing loss even of mild degree. Early diagnosis and management can overcome those negative impacts.

Objective To determine the prevalence of mild hearing loss in primary-school children and its association with their school performance.

Methods A comparative cross-sectional study was conducted at a regular school. The study included the random selection of 120 apparently normal students (aged 6-9years) who were considered as having normal hearing by their parents. A total of 20 students were excluded from the study due to the presence of wax in their ears. Finally, the study was conducted with 100 students. All participants were subjected to a basic audiological evaluation, and the Screening Instrument for Targeting Educational Risk (SIFTER) questionnaire was given to their teachers to evaluate their school performance.

Results From a total of 100 students, we confirmed that 23 (23\%) had mild hearing loss, 17 (17\%) had bilateral conductive hearing loss, and 6 (6\%) had bilateral sensorineural hearing loss. The students who had low attention and communication performance were significantly associated with mild hearing loss.

Conclusion The prevalence of mild hearing loss was of 23\% (23 cases). This problem had an effect on the communication and attention in school; and it might affect academic performance later in life. A hearing assessment is highly recommended for every child, especially those who have a low rate of academic performance.
1,000 live births. ${ }^{3,4}$ About 466 million people complain of disabling hearing loss, and 34 million of these people are children. ${ }^{5}$ Mild hearing loss is a hidden problem in most children in the age group between 1 and 9 . The prevalence of a mild hearing loss in school-age children is estimated to be between $2.4 \%$ and $14.9 \%$, according to the area of the
Copyright @ 2020 by Thieme Revinter Publicações Ltda, Rio de Janeiro, Brazil
License terms

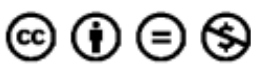


study. ${ }^{6-10}$ When a speaker is located at a distance of more than 3 feet, this may result in missing up to $10 \%$ of the speech. This percentage is susceptible to increase if there is background noise. ${ }^{6}$

Hearing loss in children, whether congenital or acquired, may be due to several causes. Congenital hearing loss may be due to genetic or non-genetic etiologies; the non-genetic factors include premature birth, birth complications, an infection in the mother during pregnancy, and maternal diabetes. More than $50 \%$ of all cases of hearing loss that occur in children are due to genetic factors, be them present at birth or developed later in life ${ }^{11}$. A total of $60 \%$ of the hearing loss that occurs in children under the age of 15 is due to preventable causes, such as exposure to loud noise and secondhand smoke, and use of audio devices. Other causes are untreated or frequent otitis media, infections like meningitis, measles, the mumps or whooping cough, in addition to taking ototoxic medications. ${ }^{12}$

Emotional and social problems can result from hearing loss even of mild degree. It also has a negative impact on the learning of verbal language, reading, writing and academic performance. Hearing loss of any type or degree can act as a barrier to incidental learning. ${ }^{13}$ Academic losses may begin when the children are in kindergarten and first grade, but those children begin to show significant learning difficulties when they reach the third grade. This difficulty may be attributed to the complexity of the language, less visual clues, more verbalizations, more need to sequence and recall, and lack of development of pre-skills in the previous grades. Mostly, these symptoms of hearing loss are mistaken for an attention deficit problem. $^{14}$

Some children do not have any physical complaints. Their parents complain only of behavioral problems, like frequent requests, improper responses to instruction, carelessness, talking too loud and confusion with similar-sounding words. However, these behavioral complaints are subjective, and are usually missed and ignored by teachers and parents, who consider that these children have normal hearing. So, identifying mild hearing loss in schoolchildren without a school hearing screening program is very difficult. ${ }^{15}$

Some countries, like Canada, have studied the importance of a hearing screening program for newborns. ${ }^{16}$

In Egypt, The prevalence of hearing loss among children is difficult to be estimated accurately because the national hearing screening program has not yet been applied, and there are only hospital-based academic studies that give just an idea about the extent of the problem. Many children with hearing loss may be missed. ${ }^{17}$

A study by Skarzyński et al $^{18}$ revealed $70 \%$ of the schoolchildren screened had peripheral hearing loss; this was the first hearing screening test in those children's lives and the families were unaware of the hearing loss in $60 \%$ of the cases. $^{18}$

The Screening Instrument for Targeting Educational Risk (SIFTER) is considered a reliable method to determine the effect of hearing loss in academic performance. Bess et $\mathrm{al}^{19}$ and Most $^{20}$ used the SIFTER questionnaire for the same purpose, and they concluded that children suffering from minimal hearing loss have a poor score in the communication domain when compared with normal-hearing children.

In developing countries like Egypt, there is no established hearing screening program for the early detection of hearing impairments. Therefore, the present study was performed to determine the prevalence of hearing loss in schoolchildren in Egypt and its association with school performance.

\section{Methods}

A comparative cross-sectional study was performed from September 2017 to March 2018. The study was conducted with 120 apparently normal students who were considered as having normal hearing by their parents and teachers. The students were selected randomly between the ages of 6 and 9 years; the children were in grades 1,2 and 3 . A total of 20 students were excluded from the study due to the presence of wax in their ears. Finally, the study was conducted with 100 students (53 boys and 47 girls) at a regular school (national Language School).

The exclusion criteria were: students who had wax in their ears or who were using hearing aid or cochlear implants; students who had chronic medical illnesses, such as diabetes mellitus, hypertension, or renal failure; students who had any disorder that may affect their academic performance, such as hyperactivity, dyslexia, or learning deficit disorder; and students who had abnormal motor development, cervical pain, back pain, or any postural change in head alignment.

All participants in the current study were subjected to the following:

1. Full history taking (history sheets were sent to all parents), including the following:

a. Personal history (age and sex).

b. History of hearing loss, tinnitus, discharge, use of hearing aid or cochlear implant.

c. Past history of systemic disease, use of ototoxic drugs, physical trauma, and operations.

2. Otological examination (performed by the author) using a handheld Riester (Jungingen, Germany) pen-scope to detect any abnormalities in external auditory canal or the tympanic membrane.

3. Basic audiological evaluation, including:

a. Immittancemetry (handheld tympanometry Zodiac 901, Interacoustics, Middelfart, Denmak) including tympanometry and acoustic reflex (AR). The tympanometry was performed at varying pressure, ranging from +200 to $-400 \mathrm{~mm}$ H2O. Acoustic reflex threshold measurements using pure tones (up to $100 \mathrm{~dB}$ ) at $500,1,000,2,000$ and 4,000 Hz elicited ipsilateral.

b. Pure-tone audiometry using a model AD226 portable audiometer (Interacoustics). It included:

- Air conduction: Air conduction hearing thresholds were determined at the frequencies of 250,500 , $1,000,2,000,4,000$ and $8,000 \mathrm{~Hz}$. 
- Bone-conduction: bone conduction hearing thresholds were determined at the frequencies of 500 , $1,000,2,000$ and $4,000 \mathrm{~Hz}$.

- Mild hearing loss was defined as an average of 20$40 \mathrm{~dB}$ at 500, 1,000, 2,000 and 4,000 $\mathrm{Hz}^{21}$

All tests were conducted in a quiet room in the school itself. Diagnostic air and bone-conduction audiometry was determined. Bone conduction was performed for students who had had air conduction $>15 \mathrm{~dB}$. The testing began at $1,000 \mathrm{~Hz}$ in the right ear at $40 \mathrm{~dB}$ HL. Thresholds were obtained using the routine $10 \mathrm{~dB}$ descending and $5 \mathrm{~dB}$ ascending method (Hughson-Westlake method). Reports on the students who had hearing loss were sent to their parents and advised them to go to an audio vestibular unit in the university hospital for reassessment and treatment.

4. The SIFTER questionnaire was given to the teachers for them to evaluate the students' school performance. (-Supplementary Material Appendix A - Available online)

This questionnaire was developed by Anderson 22 in 1989 as a screening instrument to assess school performance in children. It is composed of fifteen questions, and there are five domains (academic, attention, communication, class participation, and school behavior). Each domain is assessed by three questions. The teachers were selected according to certain criteria. They had to be teaching the children for at least one year to be considered real evaluators and to be well aware of the academic performance of the children and their personalities. The study was described to the teachers before their evaluation, which was performed during their rest period. Based on their knowledge from observations of the students, the teachers were instructed to circle the number that best represented the students' behavior.

\section{Ethical Considerations}

In the present study, all of the testing procedures were performed using non-invasive techniques, and adhering to the conditions of the Ethics in Research Committee of the institute. The history sheet and consent form were sent to the parents before the children participated in the study.

\section{Statistical Analysis}

The analysis of the data was performed using the Statistical Package for the Social Sciences (SPSS, SPSS, Inc., Chicago, IL, US), version 23. The quantitative variables, such as the mean and standard deviation (SD), and the qualitative variables were described as numbers and percentages. the $t$-test was used for the parametric data to compare the quantitative variables (SD $<50 \%$ mean). Values of $p<0.05$ were considered statistically significant. Values of $p<0.001$ were considered highly significant.

\section{Results}

\section{Demographic Data}

The age of the sample ranged from 6 to 9 years, with a mean age of 7.71 years $( \pm 0.79$ years).There were 53 females (53\%) and 47 males (47\%).

\section{Basic Audiological Assessment}

- Table 1 shows the mean pure tone hearing thresholds of the students with hearing loss in the right and left ears. The mean hearing thresholds were $>20 \mathrm{~dB}$, and they were greater in higher frequencies than in lower frequencies.

The prevalence of mild hearing loss in the school population was of $23 \%$ (23 cases; $10 \%$ [ 10 cases] of the students had bilateral conductive hearing loss [CHL], 7\% [7 cases] had unilateral CHL, and 6\% [6 cases] had bilateral sensorineural hearing loss [SNHL]). In addition, 6 (6\%) students with mild hearing loss had bilateral type-A tympanograms with preserved AR, 7 (7\%) had bilateral type-B tympanograms with absent AR, 3 (3\%) had unilateral type-B tympanograms with absent AR, 3 (3\%) had bilateral type-C tympanograms with absent AR, and 4 (4\%) had unilateral type-C tympanograms with absent AR. The 7 (7\%) students with unilateral type-B and type-C had type-A tympanograms with preserved $A R$ in the other ear.

Comparison of school performance between normalhearing students and students with mild hearing loss, between the students with unilateral and bilateral mild hearing loss, and between those with mild CHL and SNHL.

As demonstrated in - Tables 2-4 there was a statistically significant difference in communication and attention between normal-hearing students and those with mild hearing loss, and there was a statistically significant difference in academic performance between those with CHL and SNHL. But there was no statistically significant difference in school performance between the students with unilateral and bilateral mild hearing loss.

\section{Discussion}

The purpose of the current study was to determine the prevalence of mild hearing loss in primary-school children and its association with their school performance. The prevalence of

Table 1 Mean values of the pure tone thresholds of students with hearing loss

\begin{tabular}{|c|c|c|c|c|c|c|}
\hline \multirow[t]{2}{*}{ laterality } & \multicolumn{6}{|c|}{ Frequencies $(\mathrm{Hz})$} \\
\hline & 250 & 500 & 1,000 & 2,000 & 4,000 & 8,000 \\
\hline Right ear (23 ears) & $\begin{array}{l}25.2 \pm 6.5 \\
15-40\end{array}$ & $\begin{array}{l}23.5 \pm 5 \\
15-35\end{array}$ & $\begin{array}{l}26 \pm 5.1 \\
15-35\end{array}$ & $\begin{array}{l}27.9 \pm 4.3 \\
15-40\end{array}$ & $\begin{array}{l}32 \pm 4.6 .6 \\
15-40\end{array}$ & $\begin{array}{l}33.9 \pm 7.7 \\
15-40\end{array}$ \\
\hline Left ear (23 ears) & $\begin{array}{l}23.1 \pm 4.2 \\
15-35\end{array}$ & $\begin{array}{l}23.1 \pm 4.5 \\
15-35\end{array}$ & $\begin{array}{l}25.6 \pm 5 \\
15-35\end{array}$ & $\begin{array}{l}27.2 \pm 4.3 \\
15-35\end{array}$ & $\begin{array}{l}32 \pm 6.7 \\
15-40\end{array}$ & $\begin{array}{l}34.1 \pm 7.3 \\
15-40\end{array}$ \\
\hline
\end{tabular}


Table 2 Comparison of school performance between normal-hearing students and students with mild hearing loss

\begin{tabular}{|l|l|l|l|l|}
\hline School performance & Normal hearing & Mild hearing loss & $t$-test & $p$-value \\
\hline Attention & $10.97 \pm 2.562$ & $9.21 \pm 2.926$ & 2.797 & 0.0062 \\
\hline Academic & $11.00 \pm 2.066$ & $10.05 \pm 2.571$ & 1.825 & 0.070 \\
\hline Participation & $11.52 \pm 2.515$ & $10.53 \pm 2.010$ & 1.728 & 0.0871 \\
\hline Behavior & $11.55 \pm 1.895$ & $11.79 \pm 2.594$ & 0.487 & 0.627 \\
\hline Communication & $11.03 \pm 2.089$ & $9.47 \pm 2.144$ & 3.124 & 0.0023 \\
\hline
\end{tabular}

Table 3 Comparison of school performance between children with mild CHL and SNHL

\begin{tabular}{|l|l|l|l|l|}
\hline School performance & $\mathrm{CHL}$ & $\mathrm{SNHL}$ & $\boldsymbol{t}$-test & $\boldsymbol{p}$-value \\
\hline Attention & $10.29 \pm 1.65$ & $9.17 \pm 0.75$ & 1.59 & 0.125 \\
\hline Academic & $10.65 \pm 1.27$ & $9.17 \pm 0.75$ & 2.66 & 0.0145 \\
\hline Participation & $10.88 \pm 1.54$ & $10.33 \pm 0.82$ & 0.80 & 0.427 \\
\hline Behavior & $10.56 \pm 1.67$ & $10.17 \pm 1.6$ & 0.49 & 0.622 \\
\hline Communication & $10.06 \pm 1.6$ & $9 \pm 0.89$ & 1.52 & 0.142 \\
\hline
\end{tabular}

Abbreviations: $\mathrm{CHL}$, conductive hearing loss; SNHL, sensorineural hearing loss.

Table 4 Comparison of school performance between students with unilateral and bilateral mild hearing loss

\begin{tabular}{|l|l|l|l|l|}
\hline School performance & Unilateral & Bilateral & $t$-test & $p$-value \\
\hline Attention & $9.11 \pm 3.100$ & $8.30 \pm 2.869$ & 0.6086 & 0.5493 \\
\hline Academic & $10.56 \pm 2.603$ & $9.60 \pm 2.591$ & 0.8165 & 0.4234 \\
\hline Participation & $10.67 \pm 1.803$ & $10.40 \pm 2.271$ & 0.2774 & 0.7842 \\
\hline Behavior & $11.56 \pm 3.046$ & $12.00 \pm 2.261$ & 0.3868 & 0.7028 \\
\hline Communication & $9.89 \pm 2.804$ & $9.10 \pm 1.370$ & 0.9205 & 0.3678 \\
\hline
\end{tabular}

mild hearing loss was of $23 \%$ ( 23 cases) in schoolchildren aged between 6 and 9 years. This result was similar to that of a study performed in Tajikistan, ${ }^{18}$ in which 143 primary-school children were screened for hearing loss: the authors reported that about $23.7 \%$ of children had hearing loss. ${ }^{18} \mathrm{~A}$ similar result was reported in another study ${ }^{23}$ performed in Nigeria, in which the hearing threshold in 300 school-age children was assessed; the authors reported that the prevalence of low frequency was of $33.4 \% .{ }^{23}$ Khairi et al ${ }^{24}$ screened 234 schoolchildren, and found a prevalence of hearing loss of $15 \%$. Osei et $\mathrm{al}^{10}$ stated that hearing loss in basic school children is uncommon, and they found a prevalence of $11.9 \%$. In the study conducted by Bess et $\mathrm{al}^{19}$ with 1,218 children, only $11.3 \%$ complained of minimal SNHL.

In the current study, the majority of the children suffering from hearing loss ( $17 \% ; 17$ cases) had CHL (6\% [ 6 cases] with type-C tympanograms, and $11 \%$ [11 cases] with type-B tympanograms). Only 6 (6\%) students had bilateral SNHL with type-A tympanograms. Khairi et $\mathrm{al}^{24}$ reported that 88.9\% of the children with hearing loss had CHL. Hunt et $\mathrm{al}^{25}$ determined the percentage of unilateral and bilateral CHL, and the results were $24.5 \%$ and $12.5 \%$ respectively. However, Bess et $\mathrm{a}^{19}$ found different results: in their study, the rate of SNHL was of 5.4\%, and the rate of CHL was of $3.4 \%$.

The current study was conducted during autumn and winter, when the incidence of upper respiratory tract infec- tions is high; this may explain the higher prevalence of CHL in the study. Czech et $\mathrm{al}^{26}$ observed a correlation between upper respiratory tract infection and hearing loss. Additionally, the Eustachian tube is smaller and more horizontal in children than in adults, which makes it more prone to be blocked by large adenoids and infection. Until the Eustachian tube changes in size and angle, the children are more susceptible to otitis media. ${ }^{27}$

In the present study, the prevalence of SNHL was higher than that reported in previous studies. ${ }^{18-24}$ This may be attributed to the increasing use of headphones among children to listen to music and watch videos and other forms of entertainment. ${ }^{12}$ Moreover, infectious diseases such as the mumps, measles, and meningitis, as well as mechanical injuries, can cause SNHL in schoolchildren. ${ }^{28-30}$

In the current study, there was a significant difference between mild hearing loss and normal hearing in the communication and attention domains, and no significant difference in participation and behavior. In addition, the academic performance was not affected. There was a significant difference in academic performance between CHL and SNHL. This may be attributed to the fact that CHL of short duration doesn't cause a significant effect on academic performance. Bess et al ${ }^{19}$ observed poorer school performance in children with minimal hearing loss when they were compared with their 
normal-hearing peers. The school performance was affected especially in terms of attention, communication and academic performance. They also reported that about 37\% of children with minimal SNHL failed at least one grade, compared to a $2 \%$ failure rate among their normal-hearing peers; children with minimal SNHL had poorer rates regarding stress, self-esteem, and social support. Moreover, Most ${ }^{20}$ used the SIFTER questionnaire to evaluate the school performance of 47 children aged between 7.2 and 9.3 years. The children had hearing impairments of different types and degrees. He concluded that some children with unilateral hearing loss and mild hearing loss had poor school performance. The same result was reported by Hunt et al, ${ }^{25}$ who stated that chronic suppurative otitis media and hearing impairment in schoolchildren can affect their educational outcome.

Many studies showed that children with minimal and mild hearing loss may suffer from difficulties in speech perception, especially in poor listening conditions, and delays in language acquisition and social/emotional development. ${ }^{31,32}$ A study conducted by Johnson et al, ${ }^{33}$ in which the speech recognition in 12 children suffering from minimal high-frequency hearing loss was compared with that of their normal peers, the authors found a diminished score for minimal hearing loss.

Lewis et $\mathrm{al}^{34}$ assessed speech perception in eighteen children with minimal/mild hearing loss in an environment that simulated a classroom. They observed poor performance in those children when compared with normal-hearing children.

There was no significant difference in school performance between unilateral and bilateral mild hearing loss. Niskar et $\mathrm{al}^{8}$ reported that even unilateral minimal hearing loss can cause educational problems. This is in line with the results from previous studies, which reported that mild unilateral hearing loss can cause difficulties in sound localization and speech comprehension that significantly affect the learning outcome. These children do not achieve the same progress in school as their normal-hearing peers, and about $40 \%$ of schoolchildren with unilateral hearing loss may fail their final-year exams and have to repeat a class. ${ }^{35,36}$

The educational problems reported in students with mild hearing loss may be due to poor classroom acoustics, such as high reverberation and noise. This affects students with mild hearing loss more than students with normal hearing, and students with mild hearing loss require a higher signal to noise ratio in order to be able to well discriminate speech. ${ }^{37,38}$ Furthermore, with the teachers rapidly changing their location during classroom discussions and the introduction of new information can cause difficulties for children with mild hearing loss. ${ }^{39}$ Accordingly, placing children with mild hearing loss in mainstream classrooms is very important, but this must be associated with additional educational support services. ${ }^{19-40}$

With the findings of the present study, the author recommends that all teachers and parents be aware of the possible side effects of mild or unilateral hearing loss on the performance of the students in the educational system. Also, it is important to screen students with poor school performance, especially in a country that has no school hearing screening program. Finally, the conductive disorders need to be treated as early as possible, as they may have negative effects on the school performance of the children.

\section{Conclusion}

In the present study, the prevalence of mild hearing loss among primary school children was of $23 \%$ ( 23 cases). This problem affected their school performance in the communication and attention domains, and it may affect academic performance later in life. The impacts of mild hearing loss on school performance may be controlled and treated via an appropriate hearing screening protocol and program. It is highly recommended that every child undergoes a hearing assessment, especially those who have poor academic performance.

\section{Limitation}

One of the most important limitations of the present study was the sample size and the difficulty in applying the study to the whole population. There also were limitations related to the children themselves, as some parents refused to let their children participate in the study, and the poor reliability of some children due to their young age and the fear that some of them had of the examiner.

Conflicts of Interest

The author has none to disclose.

\section{References}

1 Yoshinaga-Itano C, Sedey AL, Coulter DK, Mehl AL. Language of early- and later-identified children with hearing loss. Pediatrics 1998;102(05):1161-1171

2 World Health Organization (WHO). WHO Global Estimates on Prevalence of Hearing Loss, (2012) http://www.who.int/pbd/ deafness/estimates. Accessed date: 15 March 2018

3 Finitzo T, Albright K, O'Neal J. The newborn with hearing loss: detection in the nursery. Pediatrics 1998;102(06):1452-1460

4 Van Naarden K, Decouflé P, Caldwell K. Prevalence and characteristics of children with serious hearing impairment in metropolitan Atlanta, 1991-1993. Pediatrics 1999;103(03):570-575

5 World Health Organization (WHO). Deafness and Hearing Loss, (2018) http://www.who.int/mediacentre/factsheets/fs300/en/. Accessed: March 15, 2018

6 Rao RS, Subramanyam MA, Nair NS, Rajashekhar B. Hearing impairment and ear diseases among children of school entry age in rural South India. Int J Pediatr Otorhinolaryngol 2002;64(02):105-110

7 Olusanya BO, Okolo AA, Ijaduola GTA. The hearing profile of Nigerian school children. Int J Pediatr Otorhinolaryngol 2000; 55(03):173-179

8 Niskar AS, Kieszak SM, Holmes A, Esteban E, Rubin C, Brody DJ. Prevalence of hearing loss among children 6 to 19 years of age: the Third National Health and Nutrition Examination Survey. JAMA 1998;279(14):1071-1075

9 Westerberg BD, Skowronski DM, Stewart IF, Stewart L, Bernauer M, Mudarikwa L. Prevalence of hearing loss in primary school children in Zimbabwe. Int J Pediatr Otorhinolaryngol 2005;69 (04):517-525

10 Osei AO, Larnyo PA, Azaglo A, Sedzro TM, Torgbenu EL. Screening for hearing loss among school going children. Int J Pediatr Otorhinolaryngol 2018;111:7-12 
11 World and Health Organization [WHO Web site]. Hearing loss due to recreational exposure to loud sounds: a review; 2015. Available from: http://apps.who.int/iris/bitstream/10665/154589/1/ 9789241508513 eng.pdf. Accessed: September 22, 2017

12 American Speech Language Hearing Association. Cause of hearing loss in children. Available at: http://www.asha.org/public/hearing/Causes-of-Hearing-Loss-in-Children2011

13 Wilson BS, Tucci DL, Merson MH, O’Donoghue GM. Global hearing health care: new findings and perspectives. Lancet 2017;390 (10111):2503-251510.1016/ S0140-6736(17)31073-5

14 Elizabeth C, Flexer C. Classroom Accommodations for Students with Hearing impairment. San Diego, CA: Plural Publishing, Inc.; 2007

15 Dood-Murphy J, Mamlin NMinimizing minimal hearing loss in the schools: 5- 92 (retrieved July 12, 2009), from ProQuest Central

16 Harlor AD, Bower C, Committee on Practice and Ambulatory Medicine, Section on Otolaryngol -Head and Neck Surg Collaborators, et al. Hearing assessment in infants and children: recommendations beyond neonatal screening. Pediatr 2009;124(04): 1252-1263

17 Tawfik S, Hazza N. Hearing screening in neonates: Ain Shams Experience. Paper presented at the annual meeting of the Egyptian Otolaryngolo Soc, Cairo, Egypt; September; 2004

18 Skarzyński PH, Świerniak W, Piłka A, et al. A Hearing Screening Program for Children in Primary Schools in Tajikistan: A Telemedicine Model. Med Sci Monit 2016;22:2424-2430

19 Bess FH, Dodd-Murphy J, Parker RA. Children with minimal sensorineural hearing loss: prevalence, educational performance, and functional status. Ear Hear 1998;19(05):339-354

20 Most T. The effects of degree and type of hearing loss on children's performance in class. Deafness Educ Int 2004;6(03):154-166

21 Jerger J, Jerger S. Measurement of hearing in adults. In: Paperella MM, Shumrick DA, eds. Otolaryngology. 2nd ed. Philadelphia: W. B. Saunders; 1980

22 Anderson KL. S.I.F.T.E.R.: screening instrument for targeting educational risk in children identified by hearing screening or who have known hearing loss. Tampa, FL: The Educational Audiology Association; 1989

23 Oyewumi AM, Adejumo OR. An investigation of hearing loss among school age children through audiological assessment in Ibadan, Oyo State, Nigeria. Elementary Education Online 2011;10(01):1-11

24 Khairi Md Daud M, Noor RM, Rahman NA, Sidek DS, Mohamad A. The effect of mild hearing loss on academic performance in primary school children. Int J Pediatr Otorhinolaryngol 2010;74 (01):67-70

25 Hunt L, Wakisa M, Victoria K, et al. Prevalence of pediatric chronic suppurative otitis media and hearing impairment in rural
Malawi: A cross-sectional survey. PLoS One 2017;12(12): e0188950

26 Czech D, Malicka M, Kott E, Zakrzewska A. Incidence of articulatory disorders in children with recurrent upper respiratory tract infections. Otorynolaryngologia 2011;10(03):116-120

27 Dhooge IJ. Risk factors for the development of otitis media. Curr Allergy Asthma Rep 2003;3(04):321-325

28 Skarżyński PH, Kochanek K, Skarżyński H, et al. Hearing screening program in school-age children in Western Poland. Int Adv Otol 2011;7(02):194-200

29 Yamatodani T, Mizuta K, Hosokawa K, et al. Congenital middle ear cholesteatoma: experience from 26 surgical cases. Ann Otol Rhinol Laryngol 2013;122(05):316-321

30 Nelson M, Roger G, Koltai PJ, et al. Congenital cholesteatoma: classification, management, and outcome. Arch Otolaryngol Head Neck Surg 2002;128(07):810-814

31 Bovo R, Martini A, Agnoletto M, et al. Auditory and academic performance of children with unilateral hearing loss. Scand Audiol Suppl 1988;30:71-74

32 Crandell CC. Speech recognition in noise by children with minimal degrees of sensorineural hearing loss. Ear Hear 1993; 14(03):210-216

33 Johnson C, Stein R, Broadway A, Markwalter TS. "Minimal” highfrequency hearing loss and school-age children: Speech recognition in a classroom. Lang Speech Hear Serv Sch 1997;28:77-85

34 Lewis DE, Valente DL, Spalding JL. Effect of minimal/mild hearing loss on children's speech understanding in a simulated classroom. Ear Hear 2015;36(01):136-144

35 Ross DS, Holstrum WJ, Gaffney M, Green D, Oyler RF, Gravel JS. Hearing screening and diagnostic evaluation of children with unilateral and mild bilateral hearing loss. Trends Amplif 2008; 12(01):27-34

36 Holstrum WJ, Gaffney M, Gravel JS, Oyler RF, Ross DS. Early intervention for children with unilateral and mild bilateral degrees of hearing loss. Trends Amplif 2008;12(01):35-41

37 Ruscetta MN, Arjmand EM, Pratt SR Sr. Speech recognition abilities in noise for children with severe-to-profound unilateral hearing impairment. Int J Pediatr Otorhinolaryngol 2005;69(06):771-779

38 Klatte M, Hellbrück J, Seidel J, et al. Effects of classroom acoustics on performance and well-being in elementary school children: a field study. Environ Behav 2010;42(05):659-692

39 McFadden B, Pittman A. Effect of minimal hearing loss on children's ability to multitask in quiet and in noise. Lang Speech Hear Serv Sch 2008;39(03):342-351

40 Lieu JE, Tye-Murray N, Fu Q. Longitudinal study of children with unilateral hearing loss. Laryngoscope 2012;122(09):2088-2095 